\title{
CORRESPONDENCE
}

\section{Idiopathic Scoliosis}

by Dr. med. Per Trobisch, PD Dr. med. Olaf Suess, Frank Schwab MD

in volume $49 / 2010$ accompanying the article. Many of the radiographs are easily identified as originating from (presumably) the United States, rather than Germany. For radiographic diagnostic evaluation of children, particular standards need to be adhered to for radiation protection and image quality. The German Medical Association has published a guideline (1). Adherence to this guideline, especially its paragraph relating to the specific requirements in pediatric setting is monitored by medical institutions. If the guidelines are not adhered to, measures taken range from advice to withdrawal of the license to conduct radiographic studies. In any case, an investigation will be undertaken at the affected party's expense.

The images reproduced in the article have severe deficiencies in terms of the guideline. In pediatric radiography, coning down is important. The borders of the irradiated field should be visible in the film. None of the images show a recognizable display of the irradiated area. This is particularly important in children, since they still have radiation-sensitive, hematopoietic bone marrow in almost all sections of the skeleton and should not unnecessarily be exposed to radiation due to a lack of coning down. No right or left indicator appear on the film.

In several images, no or indadequate gonadal protection was applied. In the quality control for radiological diagnostic evaluation of statutory health insurance physicians (2), this would be categorized as breaking the rules relating to gonadal protection and therefore as a severe deficiency in terms of the required quality. A rule furthermore imposes a stronger obligation to adhere to it than a guideline, which allows for deviation when the reasons are sound.

Since this CME article appeared in the journal of the German Medical Association, existing rules and guidelines should be adhered to, especially in the interests of children.

DOI: 10.3238/arztebl.2011.0189b

\section{REFERENCES}

1. Asher MA, Burton DC: Adolescent idiopathic scoliosis: natural history and long term treatment effects. Scoliosis 2006 Mar 31; 1(1): 2.

2. Weiss HR, Goodall D: Rate of complications in scoliosis surgery - a systematic review of the Pub Med literature. Scoliosis 2008; 3: 08.

3. Trobisch P, Suess 0, Schwab F: Idiopathic scoliosis. Dtsch Arztebl Int 2010; 107(49): 875-84.

Dr. med. Hans-Rudolf Weiß

Alzeyer Str. 23

55457 Gensingen, Germany

hr.weiss@skoliose-dr-weiss.com

\section{Radiographic Diagnostic Evaluation in Children}

In the diagnostic evaluation and treatment control of scoliosis, radiographic diagnosis plays an integral role, which is confirmed by the numerous radiographs

\section{REFERENCES}

1. Leitlinien der Bundesärztekammer zur Qualitätssicherung in der Röntgendiagnostik - Qualitätskriterien röntgendiagnostischer Untersuchungen - vom 23.11.2007, www.bundesaerztekammer.de/page asp?his=0.7.46

2. Richtlinien der Kassenärztlichen Vereinigung Rheinland-Pfalz zur Qualitätssicherung in der radiologischen Diagnostik einschließlich der Computertomographie durch Stichproben vom 22.11.2007 http://www.kv-rlp.de/info-center/infocenter/qualitaet/qualitaetssiche rung.html

3. Trobisch P, Suess 0, Schwab F: Idiopathic scoliosis. Dtsch Arztebl Int 2010; 107(49): 875-84.

\section{Dr. med. Cornelia Schröder}

Univ.-Prof. Dr. med/Univ Zürich Reinhard Schumacher

Förderverein „Kind und Radiologie" e.V., c/o Kinderradiologie

Prüner Gang 16-20, 24103 Kiel, Germany

mail@kind-und-radiologie.eu 


\section{In Reply:}

Our objective was to present a comprehensive overview of diverse therapeutic options. In addition to the main pillars of treatment for scoliosis in adolescents, orthotic treatment and corrective spinal fusion, we also discussed less popular options. These include, for example, Schroth physical therapy, as mentioned by Weiss, or unilateral vertebral stapling. In our article, we acknowledge the lack of studies with high levels of evidence, for conservative as well as for surgical options. We are not aware of any study with evidence level I that has documented the superiority of physical therapy over natural development for the progression of scoliosis. The level II-brace study by Katz et al that was missed by Weiss, was dealt with in an entire paragraph in our article. For this reason we cannot quite follow his criticism. In selected patients, a reduction in the progression of scoliosis from $2 / 3$ to $1 / 5$ has been observed (1).

Furthermore, Weiss claims that in an 8-year old patient with lumbar scoliosis of 45 degrees (this was confirmed in a control measurement on the original roentgenogramm), surgery could be avoided by using a full time brace. Unfortunately, this claim directly contradicts what has been reported in the current literature (1-3).

Furthermore, Weiss complains that we did not devote enough space to the therapeutic options in surgical complications. In our publication we mentioned a revision rate after surgical treatment for adolescent scoliosis of $4 \%$ (4). A more differentiated review of this topic would have its place within the remit of orthopedic literature and would have exceeded the remit of our review article. In the sense of radiation protection, we emphasized the necessity to adhere to the relevant rules and guidelines. All the images in our article originate from the US. And our department fully complies with all relevant rules and guidelines. In spite of their benefits, the irradiated area and gonadal protec- tion should not obscure the anatomy of interest. In order to be able to do a detailed orthopaedic assessment of scoliosis, it is necessary to examine the entire thorax, including the ribs, and the entire spine from the occiput all the way to the hip joints. The purpose of such investigations include the identification and assessment of possible rib anomalies or asymmetries, pelvic growth signs, a possible pelvic obliquity or a pelvic anteversion or retroversion. All factors are of vital importance to the subsequent therapeutic procedures.

In the US, each radiograph requires pagination. However, during the image editing process for the published article, these were removed in some cases. DOI: 10.3238/arztebl.2011.0190

\section{REFERENCES}

1. Katz DE, Herring JA, Browne RH, et al.: Brace wear control of curve progression in adolescent idiopathic scoliosis. J Bone Joint Surg Am 2010; 92: 1343-52.

2. Dolan LA, Weinsteil SL: Surgical rates after observation and bracing for adolescent idiopathic scoliosis: an evidence-based review. Spine 2007; 32: 91-100

3. Nachemson AL, Peterson LE: Effectiveness of treatment with a brace in girls who have adolescent idiopathic scoliosis: a prospective, controlled study based on data from the Brace Study of the Scoliosis Research Society. J Bone Joint Surg Am 1995; 77: 815-22.

4. Trobisch P, Suess 0, Schwab F: Idiopathic scoliosis. Dtsch Arztebl Int 2010; 107(49): 875-84.

\section{Dr. med. Per Trobisch}

Shriners Hospital for Children

3551 N Broad Street,

Philadelphia, PA 19140

United States

pertrobisch@gmail.com

\section{Conflict of interest statement}

The authors of all contributions declare that no conflict of interest exists according to the guidelines of the International Committee of Medical Journal Editors. 